\title{
Lung exposure to nanoparticles modulates an asthmatic response in a mouse model
}

\author{
S. Hussain ${ }^{\star, \#, f}$, J.A.J. Vanoirbeek ${ }^{\#, f}$, K. Luyts ${ }^{\#}$, V. De Vooght ${ }^{\#}$, E. Verbeken \\ L.C.J. Thomassen ${ }^{+}$, J.A. Martens ${ }^{+}$, D. Dinsdale ${ }^{\S}$, S. Boland*, F. Marano*, \\ B. Nemery\# and P.H.M. Hoet ${ }^{\#}$
}

ABSTRACT: The aim of this study was to investigate the modulation of an asthmatic response by titanium dioxide $\left(\mathrm{TiO}_{2}\right)$ or gold $(\mathrm{Au})$ nanoparticles (NPs) in a murine model of diisocyanateinduced asthma.

On days 1 and $8, B A L B / c$ mice received $0.3 \%$ toluene diisocyanate (TDI) or the vehicle acetoneolive oil (AOO) on the dorsum of both ears $(20 \mu \mathrm{L})$. On day 14 , the mice were oropharyngeally dosed with $40 \mu \mathrm{L}$ of a NP suspension $\left(0.4 \mathrm{mg} \cdot \mathrm{mL}^{-1}\left(\sim 0.8 \mathrm{mg} \cdot \mathrm{kg}^{-1}\right) \mathrm{TiO}_{2}\right.$ or $\left.\mathrm{Au}\right)$. 1 day later (day $15)$, the mice received an oropharyngeal challenge with $0.01 \%$ TDI $(20 \mu \mathrm{L})$. On day 16, airway hyperreactivity (AHR), bronchoalveolar lavage (BAL) cell and cytokine analysis, lung histology, and total serum immunoglobulin $\mathrm{E}$ were assessed.

NP exposure in sensitised mice led to a two- $\left(\mathrm{TiO}_{2}\right)$ or three-fold (Au) increase in $\mathrm{AHR}$, and a three- $\left(\mathrm{TiO}_{2}\right)$ or five-fold $(\mathrm{Au})$ increase in $\mathrm{BAL}$ total cell counts, mainly comprising neutrophils and macrophages. The NPs taken up by BAL macrophages were identified by energy dispersive X-ray spectroscopy. Histological analysis revealed increased oedema, epithelial damage and inflammation.

In conclusion, these results show that a low, intrapulmonary doses of $\mathrm{TiO}_{2}$ or $\mathrm{Au}$ NPs can aggravate pulmonary inflammation and AHR in a mouse model of diisocyanate-induced asthma

KEYWORDS: Diisocyanate-induced asthma, gold, nanoparticle, titanium dioxide, toluene diisocyanate

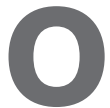
ccupational asthma accounts for an important percentage of work-related respiratory illnesses [1]. It has been reported that at least $9-15 \%$ cases of asthma in adults are due to occupational exposures [2]. Isocyanates are widely used in various industrial and consumer products, and they are a major cause of chemical-induced occupational asthma throughout the world [3].

We have previously described a mouse model of chemical-induced asthma using toluene diisocyanate (TDI) as sensitising agent [4-6]. In this mouse model, we initiate sensitisation via dermal application, which is followed by a single airway challenge, resulting in asthma-like responses. In obstructive asthma, it is generally assumed that exposure in the respiratory tract is the key route and site for the initiation of the immune responses. However, despite reductions in workplace respiratory exposures, isocyanate asthma continues to occur, and this has prompted a focus on skin as a route of exposure [3, 7-9]. Recently, several animal models have shown convincingly that skin exposure to chemical sensitisers (predominantly isocyanates, but also anhydrides and persulfate salts) can induce systemic sensitisation, which may result in asthmalike respiratory responses when the animal is later challenged via the airways [5, 10-12].

Current estimates indicate that $>800$ nanomaterialcontaining products are commercially available, according to the Woodrow Wilson Database [13]. These nanomaterials can affect health through consumer products, and occupational and environmental exposures $[14,15]$. Both titanium dioxide $\left(\mathrm{TiO}_{2}\right)$ and gold $(\mathrm{Au})$ nanoparticles (NPs) are produced and used in substantial quantities, and pose an emergent occupational and consumer risk [13]. $\mathrm{TiO}_{2}$ NPs are one of the most abundantly produced and widely utilised nanomaterials [16], with applications in sunscreens, cosmetics, tooth pastes and food products $[17,18]$. The biological

\section{AFFILIATIONS}

*Laboratory of Molecular and Cellular Responses to Xenobiotics, Unit of Functional and Adaptive Biology, University of Paris Diderot, Paris, France.

${ }^{\#}$ Research Unit for Lung Toxicology.

"Morphology and Molecular

Pathology Section, and

${ }^{+}$Center for Surface Chemistry \&

Catalysis, KU Leuven, Leuven,

Belgium.

${ }^{\S}$ MRC Toxicology Unit, University of Leicester, Leicester, UK.

${ }^{f}$ These authors contributed equally to the study.

CORRESPONDENCE

P.H.M. Hoet

Research Unit for Lung Toxicology, Dept of Occupational, Environmental and Insurance Medicine

KU Leuven

Herestraat 49 bus 706

3000 Leuven

Belgium

E-mail: peter.hoet@med.kuleuven.be

Received:

Oct 232009

Accepted after revision:

May 202010

First published online:

June 072010 
applications of Au NPs have been recently reviewed [19]. Au NPs are used medicinally as drug-delivery agents [20], in the treatment of rheumatoid arthritis [21], for photodynamic therapy of cancer [22] and as antimicrobial agents [23].

Modulation of pulmonary illnesses by a variety of occupational and environmental factors has been a topic of interest in the recent past. Previous knowledge of air pollution studies confirm the role of NPs in aggravating pulmonary illnesses [24]. A correlation between the use of asthma medication, which has been linked to lung function disturbances, with environmental NP exposure has been reported [25]. Indeed, different types of engineered NPs have been shown to induce pulmonary inflammation in experimental animals [26, 27] and cell lines of respiratory origin in vitro [28-31].

We hypothesised that, like environmental particulate material, engineered NPs will enhance the inflammatory response in asthmatic subjects. In the present study, we investigated the modulation of airway hyperreactivity and inflammatory response by $\mathrm{TiO}_{2}$ or $\mathrm{Au}$ in a mouse model of diisocyanateinduced asthma.

\section{MATERIALS AND METHODS}

\section{NPs}

$\mathrm{TiO}_{2}$ NPs (99.9\% anatase) of $15 \mathrm{~nm}$ primary particle size were obtained from Sigma-Aldrich (Saint Quentin Fallavier, France). Au NPs of $40 \mathrm{~nm}$ primary particle size were prepared in the laboratory (Institut d'Electronique Fondamentale, Universite Paris-Sud, Orsay, France) by the Turkevich method. Briefly, an aqueous solution of Au-tetrachloroauric acid (82.8 $\mathrm{mg}$ of gold) was heated until boiling under vigorous stirring. Then, an aliquot of a $1 \%$ aqueous trisodium citrate solution was added, and the solution was stirred and kept at boiling point for a further $45 \mathrm{~min}$. Au NPs with average sizes of $40 \mathrm{~nm}$ were prepared by adjusting the ratio of $\mathrm{AuCl}_{4}$ to citrate from 0.4 to 1.3 . After the introduction of the citrate solution, a purple colour appeared, which then turned to ruby red. The solution was then stirred and kept at boiling point for a further $45 \mathrm{~min}$ to complete the reduction process.

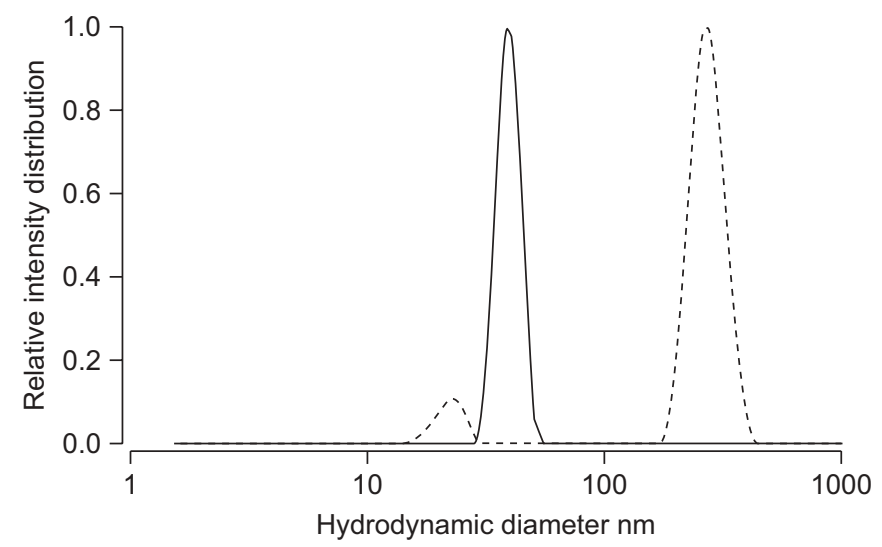

FIGURE 1. Dynamic light scattering analysis of gold ( - ) and titanium dioxide (---) nanoparticles.
In all experiments, NP suspensions $\left(0.04 \mu \mathrm{g} \cdot \mathrm{mL}^{-1}\right)$ stabilised in $2.5 \mathrm{mM}$ trisodium citrate tribasic dehydrate (vehicle; SigmaAldrich, Steinheim, Germany) were utilised to treat the mice.

\section{NP characterisation}

NPs were thoroughly characterised for their purity, hydrodynamic diameters, $\zeta$ potentials, spectral characteristics, electrophoretic mobility, and primary particle diameter and behaviour in solution form (transmission electron microscopy (TEM)).

\section{TEM}

TEM measurements were performed using a Philips CM30 TEM (Philips FEI, Eindhoven, The Netherlands) operating at $300 \mathrm{kV}$. Small volumes of sample (same concentration of NPs used to expose the mice, dissolved in trisodium citrate) were deposited on copper mesh grids and covered with carbon coating films. The samples were then dried under a nitrogen atmosphere in a glove box.

\section{Dynamic light scattering}

$\mathrm{Au}$ and $\mathrm{TiO}_{2}$ NPs were diluted to concentrations of 40 and $8 \mathrm{mg} \cdot \mathrm{L}^{-1}$, respectively, in $2.5 \mathrm{mM}$ trisodium citrate solution, followed by ultrasonic treatment to reduce agglomeration. Homogeneous suspensions were obtained. Dynamic light scattering (DLS) measurements were performed with a Brookhaven 90 Plus NanoParticle Size Distribution Analyser (scattering angle $90^{\circ}$, wavelength $659 \mathrm{~nm}$, power $15 \mathrm{~mW}$; Brookhaven Instruments Ltd, Redditch, UK). Correlation functions were analysed using the Clementine package (maximum entropy method) for Igor Pro 6.02A (WaveMetrics, Portland, OR, USA). This resulted in intensity-weighted distribution functions versus decay times. By converting the decay times with instrument parameters and physical parameters to hydrodynamic diameters, an intensity-weighted size distribution is obtained. A log-normal fit was applied to each population, resulting in the intensity-weighed average hydrodynamic diameter of the population. Note that the hydrodynamic diameter is the kinetic unit comprising the bare particles and a solvation layer. It is a value that refers to how fast a particle diffuses within a fluid. It corresponds to the diameter of a sphere that has the same translational diffusion coefficient as the particle. Mass- and number-weighted distributions were estimated using the Rayleigh scattering approximation and a correction factor for the form-factor of spherical particles [32].

\section{$\zeta$ potential measurements \\ $\zeta$ potential measurements were performed on the same NP solutions as used for DLS. $\mathrm{Au}$ and $\mathrm{TiO}_{2} \mathrm{NPs}$ were diluted to concentrations of 40 and $8 \mathrm{mg} \cdot \mathrm{L}^{-1}$, respectively, in $2.5 \mathrm{mM}$ trisodium citrate solution ( $\mathrm{pH} 6.95$, ionic strength $(I)=15 \mathrm{mM})$. $\zeta$ potential was measured with a Brookhaven 90Plus/ZetaPlus instrument applying electrophoretic light scattering. A pri- mary and reference beam ( $659 \mathrm{~nm}, 35 \mathrm{~mW})$, modulated optics and a dip-in electrode system were used. The frequency shift of scattered light (relative to the reference beam) from a charged particle moving in an electric field is related to the electrophoretic mobility of the particle. The Smoluchowski limit was used to calculate the $\zeta$ potential from the electro- phoretic mobility.}


a)

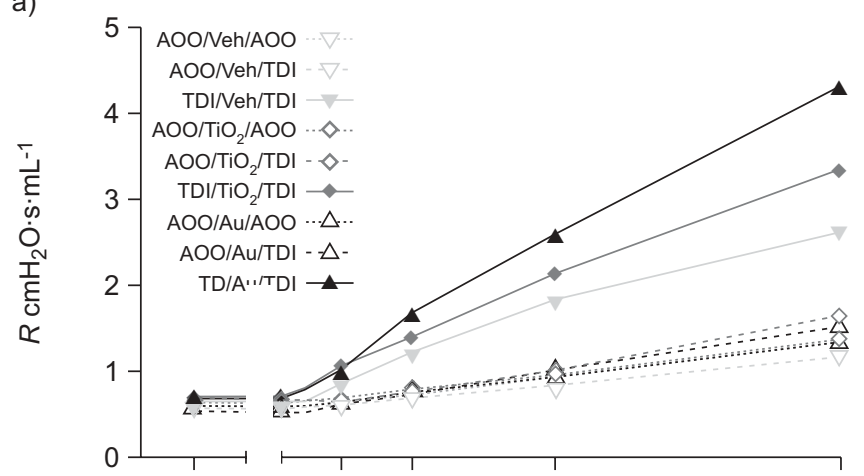

c)

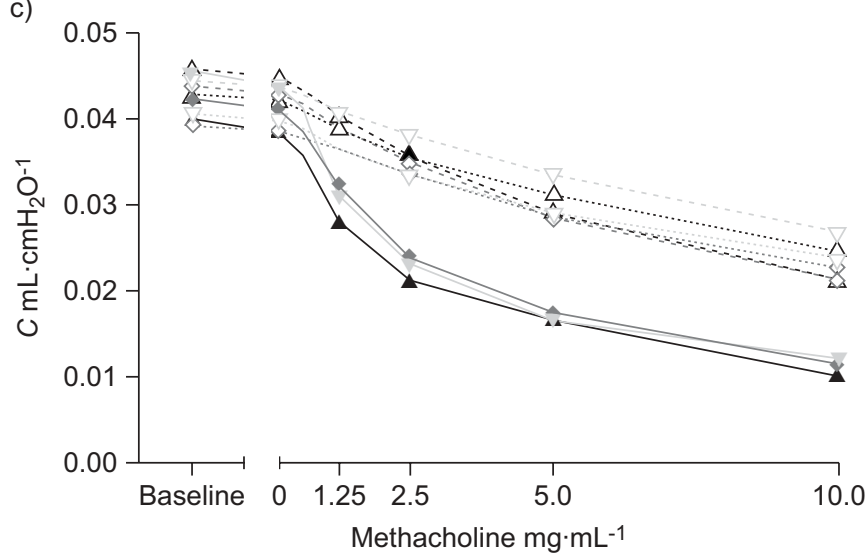

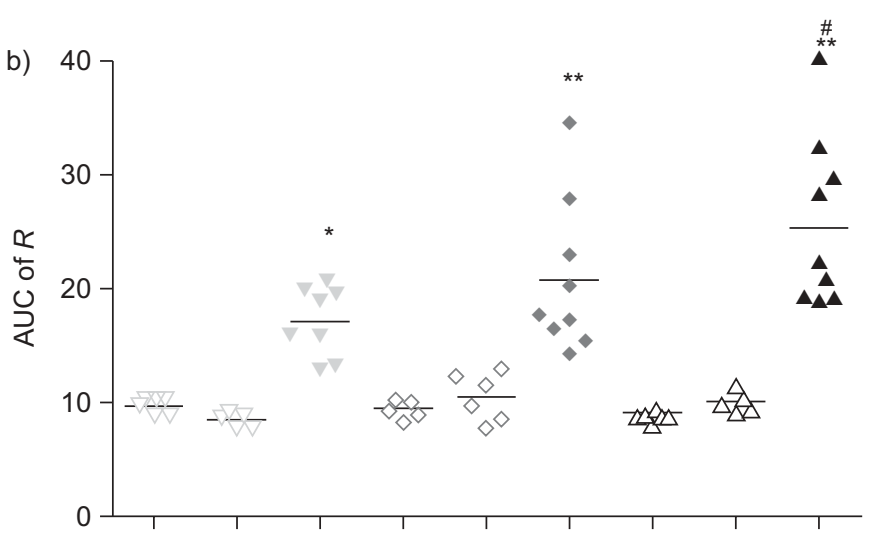

d)

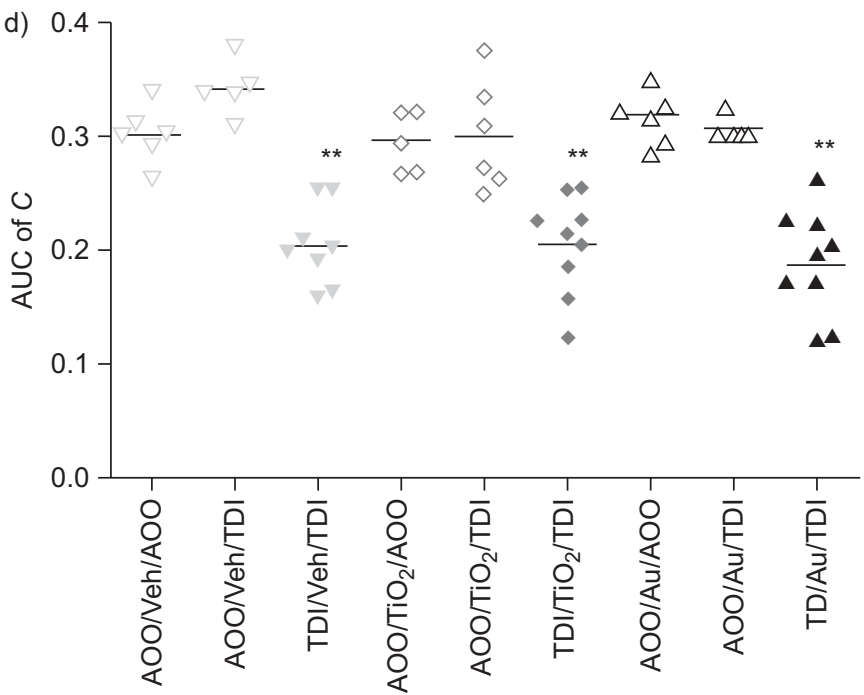

FIGURE 2. Airway hyperreactivity a) airway resistance $(R)$ and c) compliance $(C)$ to methacholine exposure was measured by the forced oscillation technique $22 \mathrm{~h}$ after the toluene diisocyanate (TDI) challenge. Area under curve (AUC) of b) $R$ and d) $C$ are shown. Experimental groups were acetone (A)-olive oil (OO)/vehicle (Veh)/AOO), AOO/ Veh/TDI, TDI/Veh/TDI, AOO/titanium dioxide $\left(\mathrm{TiO}_{2}\right) / \mathrm{AOO}, \mathrm{AOO} /\left(\mathrm{TiO}_{2}\right) / \mathrm{TDI}, \mathrm{TDI} / \mathrm{TiO}_{2} / \mathrm{TDI}, \mathrm{AOO} / \mathrm{gold}(\mathrm{Au}) / \mathrm{AOO}, \mathrm{AOO} / \mathrm{Au} / \mathrm{TDI}$ and TDI/Au/TDI. The first abbreviation indicates the agent used for dermal application on days 1 and 8 , the second abbreviation indicates type of nanoparticle/Neh exposure on day 14 (oropharyngeal route) and the third abbreviation indicates the TDI challenge on day 15 (oropharyngeal route). Data are presented as $a, c)$ mean and $b, d$ ) individual values and group means ( - ). $n=5-9$. *: $p<0.05$ compared with AOONeh/AOO; **: $p<0.01$ compared with AOONeh/AOO; ${ }^{*}: p<0.01$ compared with the TDI/Neh/TDI group.

\section{Reagents}

Toluene-2,4-diisocyanate (TDI; 98\%; Fluka, CAS 584-84-9), acetyl- $\beta$-methylcholine (methacholine) and acetone were obtained from Sigma-Aldrich (Bornem, Belgium). Pentobarbital (Nembutal) was obtained from Sanofi Santé Animale (CEVA, Brussels, Belgium) and Isoflurane (Forene $\left.{ }_{\Re}\right)$ from Abbott Laboratories (SA Abbott NV, Ottignies, Belgium). The vehicle used to dissolve TDI consisted of a mixture of two volumes of acetone (A) and three volumes of olive oil (OO) (extra virgin; Carbonell, Spain) for the dermal sensitisation, and one volume of acetone and four volumes of olive oil for the challenge. Concentrations of TDI are given as \% (volume/volume) in AOO.

\section{Animals}

Male BALB/c mice ( $\sim 20 \mathrm{~g}, 6$ weeks old) were obtained from Harlan (Horst, The Netherlands). The mice were housed in a conventional animal house with 12-h dark/light cycles. They received lightly acidified water and pelleted food (Trouw Nutrition, Ghent, Belgium) ad libitum. All experimental procedures were approved by the local Ethical Committee for Animal Experiments (Katholieke Universiteit Leuven, Leuvin, Belgium).

\section{Experimental protocol}

On days 1 and 8, mice were dermally sensitised with $0.3 \%$ TDI or vehicle $(2: 3 \mathrm{AOO})(20 \mu \mathrm{L})$ on the dorsum of both ears. On day $14,40 \mu \mathrm{L} \mathrm{NP}$ suspensions $\left(\sim 0.8 \mathrm{mg} \cdot \mathrm{kg}^{-1} \mathrm{TiO}_{2}\right.$ and $\left.\mathrm{Au}\right)$ or $2.5 \mathrm{mM}$ trisodium citrate (vehicle) were given via oropharyngeal aspiration under light isoflorane anaesthesia. On day 15 , the mice were challenged oropharyngeally with $0.01 \%$ TDI as described previously [33]. On day 16, methacholine provocation was performed with the collection of bronchoalveolar lavage (BAL), blood and lung tissue for histology.

Experimental groups were designated as AOO/Veh/TDI, $\mathrm{TDI} / \mathrm{Veh} / \mathrm{TDI}, \mathrm{AOO} / \mathrm{TiO}_{2} / \mathrm{TDI}, \mathrm{TDI} / \mathrm{TiO}_{2} / \mathrm{TDI}, \mathrm{AOO} / \mathrm{Au} /$ TDI and TDI/Au/TDI. The first abbreviation indicates the agent used for dermal application on days 1 and 8, the second abbreviation indicates type of $\mathrm{NP} /$ vehicle (Veh) exposure on 


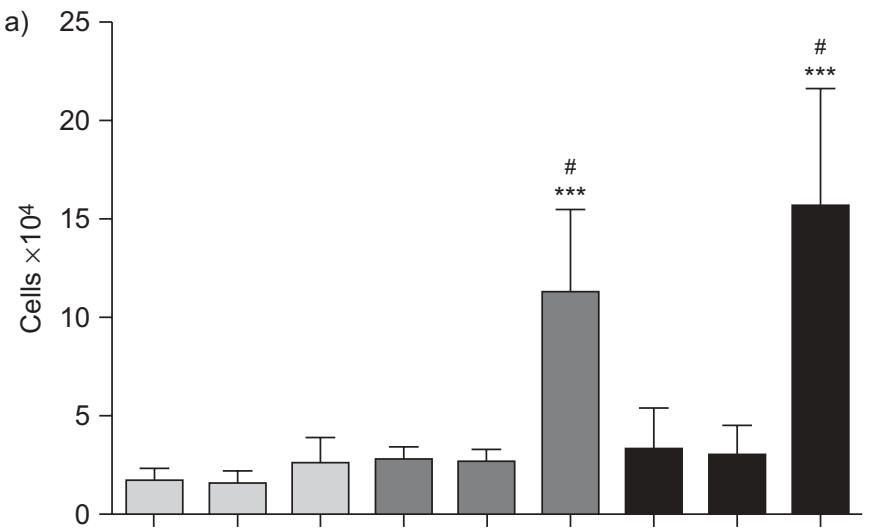

b) $15-$
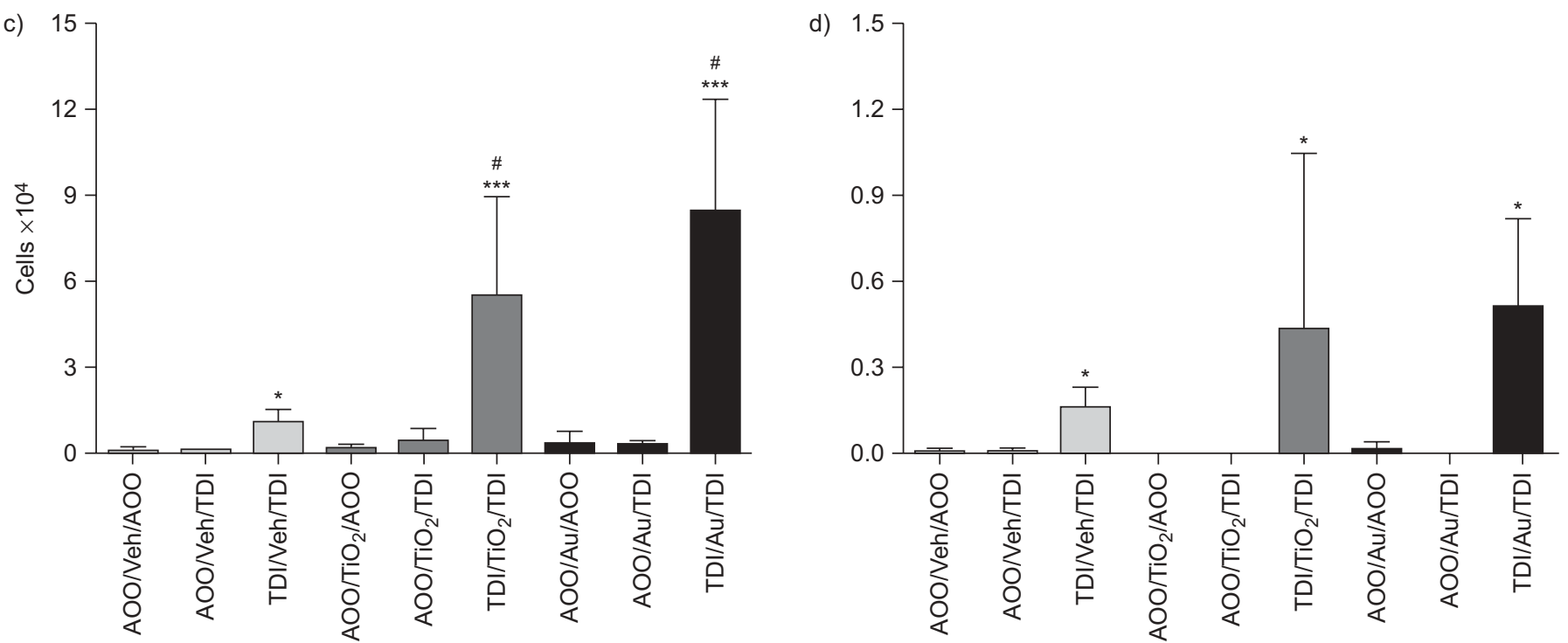

FIGURE 3. Total and differential bronhoalveolar lavage (BAL) cell counts. BAL fluid was collected $24 \mathrm{~h}$ after the toluene diisocyanate (TDI) challenge. a) total cell, b) macrophage, c) neutrophil and d) eosinophil counts are shown. Experimental groups are identical to figure 2. Data are presented as mean \pm SD. $n=5-9$ per group. A acetone; OO: olive oil; Veh: vehicle; $\mathrm{TiO}_{2}$ : titanium dioxide; Au: gold. *: $\mathrm{p}<0.05$ compared with $\mathrm{AOONeh/AOO;} \mathrm{**:} \mathrm{p}<0.01$ compared with $\mathrm{AOO} / \mathrm{Neh} / \mathrm{AOO}$; ***: $\mathrm{p}<0.001$ compared with AOONeh/AOO; *: p<0.001 compared with TDINeh/TDI.

day 14 (oropharyngeal route) and the third abbreviation indicates the TDI challenge on day 15 (oropharyngeal route).

\section{Airway hyperreactivity}

Airway hyperreactivity (AHR) to methacholine was assessed $22 \mathrm{~h}$ after the TDI challenge, using a forced oscillation technique (FlexiVent; SCIREQ, Montreal, Canada). As previously described, airway resistance $(R)$ and compliance (C) were measured using a "snapshot" protocol. For each mouse, $R$ and $C$ were plotted against methacholine concentration $\left(0-10 \mathrm{mg} \cdot \mathrm{mL}^{-1}\right)$ and the area under the curve (AUC) was calculated [34].

\section{$B A L$}

\section{Cell counts}

On day 16 ( $22 \mathrm{~h}$ after the TDI challenge and directly after the AHR test), the mice were sacrificed using an overdose (90 $\mathrm{mg} \cdot \mathrm{kg}^{-1}$ i.p.) of pentobarbital, blood was sampled from the retro-orbital plexus and a BAL was performed, as described previously [33]. Total and differential cell counts were performed and the BAL supernatant was frozen $\left(-80^{\circ} \mathrm{C}\right)$ until further use.

\section{Endocytosis estimation}

To estimate the extent of the phagocytosis of the particles, $\geqslant 200$ macrophages were randomly counted for the microscopically visible presence or absence of NP aggregates inside the cytoplasm at $1000 \times$ magnification.

\section{Electron microscopy and microanalysis}

Cytospin slides were rinsed in xylene to remove immersion oil and embedded using an inverted gelatin capsule of Taab epoxy resin (Taab Laboratories Equipment Ltd, Aldermaston, UK). The polymerised block was removed from the slide and sectioned. Ultrathin sections from BAL of mice exposed to $\mathrm{Au}$ NPs were mounted on titanium grids, and sections from control and $\mathrm{TiO}_{2}$-exposed animals were mounted on copper grids. All sections were examined using a Megaview 3 digital camera and iTEM software (Olympus Soft Imaging Solutions $\mathrm{GmbH}$, Münster, Germany) in a Jeol 100-CXII electron 
TABLE 1 Bronchoalveolar lavage (BAL) cytokines

\begin{tabular}{|c|c|c|c|c|c|}
\hline Experimental group & MMP-9 ng $\cdot \mathrm{mL}^{-1}$ & MIP-2 pg $\cdot \mathrm{mL}^{-1}$ & $\mathrm{MCP}-1 \mathrm{pg} \cdot \mathrm{mL}^{-1}$ & $\mathrm{TNF}-\alpha \mathrm{pg} \cdot \mathrm{mL}^{-1}$ & $\mathrm{IL}-6 \mathrm{pg} \cdot \mathrm{mL}^{-1}$ \\
\hline AOO/Veh/AOO & $0.14 \pm 0.26$ & $9.66 \pm 1.91$ & $17.17 \pm 7.75$ & $371.0 \pm 170.9$ & $220.4 \pm 67.1$ \\
\hline TDI/Veh/TDI & $2.55 \pm 2.30^{*}$ & $15.45 \pm 6.74$ & $24.38 \pm 8.55$ & $524.3 \pm 226.1$ & $136.9 \pm 74.8$ \\
\hline $\mathrm{AOO} / \mathrm{TiO}_{2} / \mathrm{AOO}$ & $0.62 \pm 0.43$ & $9.52 \pm 0.67$ & $15.71 \pm 8.28$ & $360.5 \pm 129.4$ & $206.2 \pm 63.7$ \\
\hline $\mathrm{AOO} / \mathrm{TiO}_{2} / \mathrm{TDI}$ & $1.81 \pm 2.06$ & $10.62 \pm 2.14$ & $26.37 \pm 13.37$ & $1111.0 \pm 649.0$ ** & $265.3 \pm 119.4$ \\
\hline $\mathrm{AOO} / \mathrm{Au} / \mathrm{TDI}$ & $2.68 \pm 2.78$ & $13.62 \pm 3.85$ & $31.91 \pm 11.93$ & $957.2 \pm 490.5^{\star}$ & $300.6 \pm 114.4$ \\
\hline TDI/Au/TDI & $4.56 \pm 1.57^{\star \star}$ & $20.25 \pm 7.89 * *$ & $29.89 \pm 17.96$ & $189.8 \pm 127.1^{\#}$ & $71.4 \pm 81.1^{*}$ \\
\hline
\end{tabular}

Data are presented as mean \pm SD. Concentrations of matrix metallopeptidase (MMP)-9, macrophage inflammatory protein (MIP)-2, monocyte chemotactic protein (MCP)-1, tumour necrosis factor (TNF)- $\alpha$ and interleukin (IL)-6 were measured in BAL via standard ELISA. Experimental groups are identical to figure 2. $n=5-9$ per group. $\mathrm{A}$ : acetone; OO: olive oil; Veh: vehicle; TDI: toluene diisocyanate; $\mathrm{TiO}_{2}$ : titanium dioxide; Au: gold. *: $\mathrm{p}<0.05$ compared with $\mathrm{AOONeh/AOO;} \mathrm{**:} \mathrm{p}<0.01$ compared with AOONeh/AOO; ${ }^{*}: p<0.05$ compared with TDINeh/TDI.

microscope (Jeol UK Ltd, Welwyn Garden City, UK) equipped with a PCXA-1186 energy-dispersive X-ray (EDX) spectrometer (Link Analytical Ltd, High Wycombe, UK).

\section{Cytokine analysis}

Levels of matrix metallopeptidase (MMP)-9, macrophage inflammatory protein (MIP)-2 (both R\&D Systems, Abingdon, UK), tumour necrosis factor (TNF)- $\alpha$, monocyte chemotactic protein (MCP)-1 and interleukin (IL)-6 (all Invitrogen SA, Merelbeke, Belgium) were measured in undiluted BAL fluid by a sandwich ELISA, according to the manufacturers' instructions. Lower limits of detection were $0.007 \mathrm{ng} \cdot \mathrm{mL}^{-1}$, $1.5 \mathrm{pg} \cdot \mathrm{mL}^{-1}, 3 \mathrm{pg} \cdot \mathrm{mL}^{-1}, 9 \mathrm{pg} \cdot \mathrm{mL}^{-1}$ and $3 \mathrm{pg} \cdot \mathrm{mL}^{-1}$, respectively.

\section{Histological lesion scoring}

After collection of BAL fluid, lungs were filled in situ with $4 \%$ formaldehyde until all lobes were fully inflated, as judged visually. Blind scoring for lung injury was done by an experienced pathologist based on the presence of oedema, infiltrates of macrophages and neutrophils, and epithelial damage on haematoxylin and eosin (H\&E)-stained slides.

\section{Total serum immunoglobulin $E$}

Total serum immunoglobulin (Ig)E concentration was measured using the OptEIA ${ }^{\mathrm{TM}}$ Mouse IgE set (Pharmingen; BD Biosciences, Erembodegem, Belgium) after 1 in 70 dilution, according to the manufacturer's recommendations.

\section{Statistical analysis}

Data are presented as mean $\pm \mathrm{SD}$, except for the AUC data for AHR, which is shown as individual mouse data and group means. All groups were tested for normality using the Kolmogorov-Smirnov normality test. Additionally, the larger TDI groups $(n=8-9)$ were tested using the D'Agostino and Pearson omnibus normality test and the Shapiro-Wilk normality test. Since our data were normally distributed, we applied an ANOVA followed by Bonferroni test for multiple comparisons using Graphpad (Graphpad Prism 4.01; Graphpad Software Inc., San Diego, CA, USA). A level of $p<0.05$ (twotailed) was considered significant.

\section{RESULTS}

\section{NP characteristics}

NPs were thoroughly characterised before use, which we described previously $[28,31]$. The $\zeta$ potentials for $\mathrm{Au}$ and $\mathrm{TiO}_{2}$ $\mathrm{NPs}$ in $2.5 \mathrm{mM}$ trisodium citrate were -74 and $-52 \mathrm{mV}$, respectively, showing that electrostatic repulsions may be an important factor in stabilising the suspensions. These large negative $\zeta$ potentials of the particles in comparison with $\zeta$ potentials in water (data not shown) demonstrate the stabilising effect of the citrate solution, particularly towards the $\mathrm{Au}$ NPs. Analysis of homogeneous suspensions of the nanoparticles in a $2.5 \mathrm{mM}$ trisodium citrate solution by DLS showed a single population of 40-nm Au particles and two populations in the $\mathrm{TiO}_{2}$ samples. Primary $\mathrm{TiO}_{2}$ particles with a hydrodynamic diameter of $22 \mathrm{~nm}$ were detected next to agglomerates or aggregates with a mean hydrodynamic diameter of $272 \mathrm{~nm}$ (fig. 1). On a number basis, $<0.01 \%$ of the particles were agglomerates or aggregates. On a mass basis, $23.8 \%$ of the mass was in agglomerates or aggregates. We can conclude that the majority of $\mathrm{TiO}_{2}$ particles exist as isolated primary particles in the suspension.

\section{AHR}

Figure 2a (resistance) and c (compliance) show the airway responsiveness to methacholine measured $22 \mathrm{~h}$ after the TDI challenge (day 16). The mean AUC of each group is shown in figure $2 \mathrm{~b}$ and $\mathrm{d}$, for resistance and compliance, respectively. There were no differences between the six non-sensitised groups. All TDI-sensitised and -challenged groups (TDI/Veh/TDI, TDI/ $\mathrm{TiO}_{2} / \mathrm{TDI}$ and TDI/Au/TDI) were significantly increased compared to the complete control group (AOO/Veh/AOO). When comparing TDI-sensitised and -challenged mice, only $\mathrm{Au}$ NP-exposed mice (TDI/Au/TDI) showed increased AHR (resistance, but not compliance) compared to the TDI/Veh/TDI group.

\section{$B A L$}

Total cell counts are presented in figure 3a. TDI-sensitised, -challenged and NP-exposed mice (TDI/ $\mathrm{TiO}_{2} / \mathrm{TDI}$ and TDI/ $\mathrm{Au} / \mathrm{TDI}$ ) showed a significantly higher total BAL cell count 

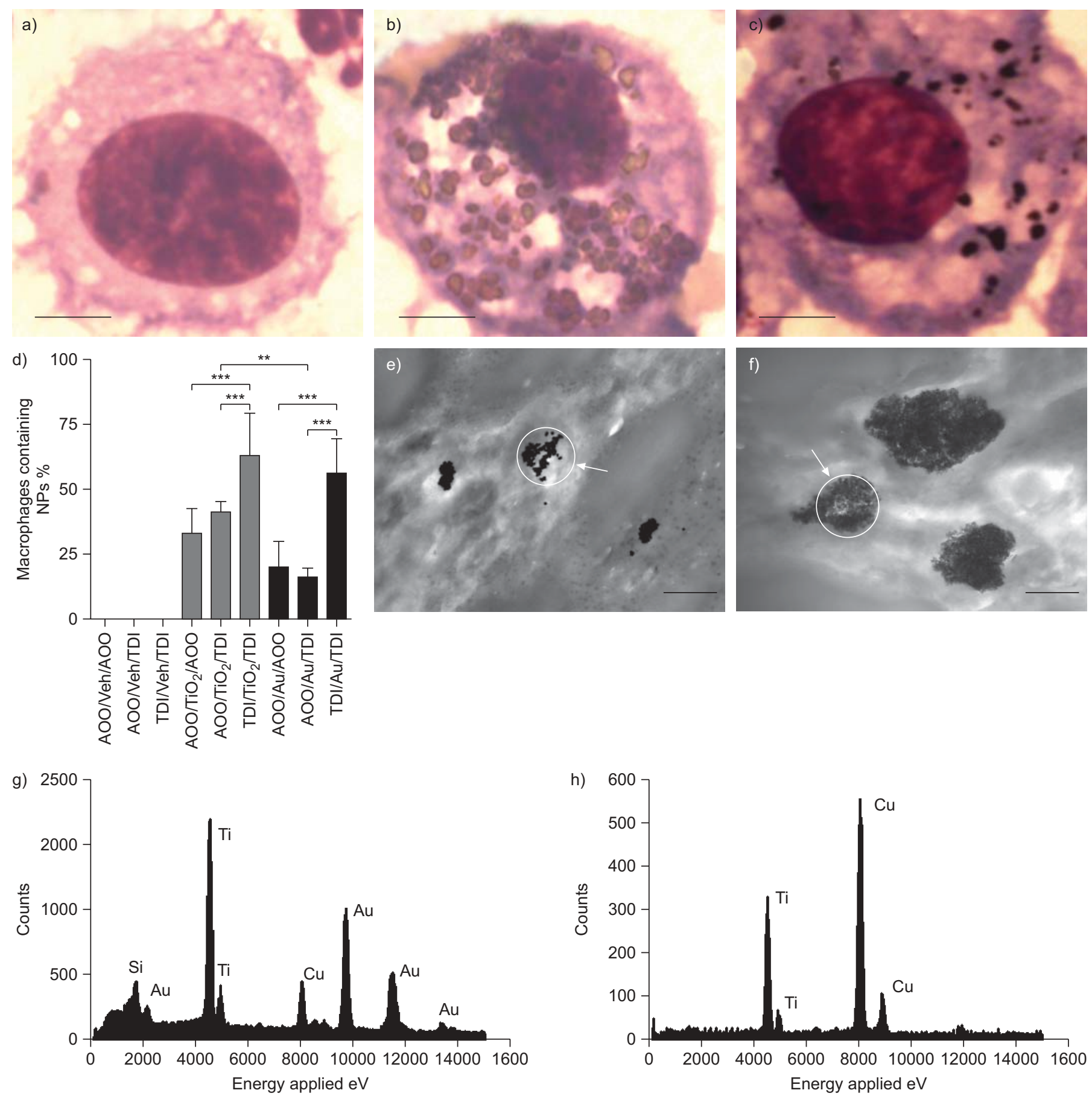

FIGURE 4. Nanoparticle (NP) uptake by bronchoalveolar lavage macrophages and analysis of internalised particles. Representative images of one macrophage from the a) toluene diisocyanate (TDI)/vehicle (Veh)/TDI, b) TDI/titanium dioxide $\left(\mathrm{TiO}_{2}\right) / \mathrm{TDI}$ and c) TDI/gold (Au)/TDI groups. Scale bars $=2.5 \mu \mathrm{m}$. d) Percentage of macrophages with NPs in their cytoplasm. ${ }^{*}: p<0.01$; ${ }^{* *}: p<0.01$. Transmission electron micrographs showing clusters of electron-dense particles in the cytoplasm of a macrophage from a mouse exposed to e) $\mathrm{Au}$ or f) $\mathrm{TiO}_{2} \mathrm{NPs}$. Scale bars $=5 \mu \mathrm{m}$. g) $X$-ray spectrum from the area indicated by the circle and arrow in e), showing the $M \alpha L \alpha \beta_{1}$ and $L \beta_{2}$ peaks for Au together with the $\mathrm{K} \alpha$ and $\mathrm{K} \beta$ peaks for titanium (Ti; grid) and background peaks for copper ( $\mathrm{Cu}$ ) and silicon (Si). $\mathrm{h}$ ) X-ray spectrum from the area indicated by the circle and arrow in $\mathrm{f}$ ), showing the $\mathrm{K} \alpha$ and $\mathrm{K} \beta$ peaks for Ti together with the $\mathrm{K} \alpha$ and $\mathrm{K} \beta$ peaks for $\mathrm{Cu}$ (grid). Experimental groups are identical to figure 2. $\mathrm{n}=5-6$. A: acetone; OO: olive oil.

compared with the complete control groups (AOO/Veh/ AOO). TDI-sensitised and -challenged mice with NP (both $\mathrm{TiO}_{2}$ and $\mathrm{Au}$ ) exposure showed a significantly higher inflammation compared with TDI-sensitised mice without $\mathrm{NP}$ exposure. Total macrophage counts are presented in figure $3 \mathrm{~b}$, and show the same trends and significant differences as the total BAL cell count. Total neutrophil and eosinophil counts are presented in figure $3 c$ and $d$, respectively. TDI sensitisation and challenge led to significant influx of neutrophils and eosinophils in BAL compared with the 

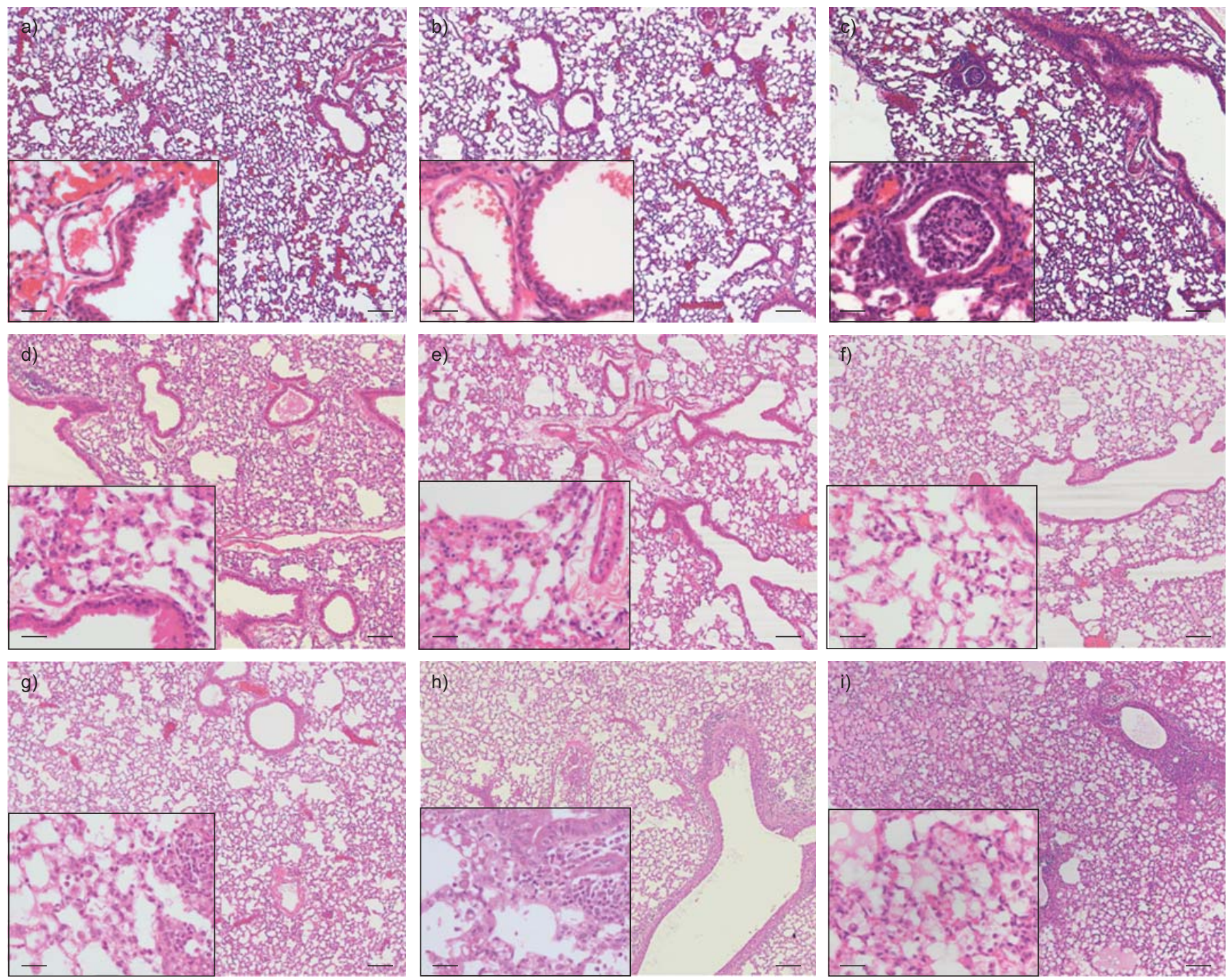

FIGURE 5. Histological analysis of lung tissue. Lungs were isolated and fixed with formaldehyde. Semifine sections were cut after paraffin embedding. Slides were stained with haematoxylin and eosin, and analysed for pathological lesions. Scale bars $=400 \mu \mathrm{m}$ at $40 \times$ magnification and $100 \mu \mathrm{m}$ at $400 \times$ magnification (inset). Experimental groups are identical to figure 2: a) acetone (A)-olive oil (OO)/vehicle (Veh)/AOO; b) AOO/titanium dioxide $\left.\left(\mathrm{TiO}_{2}\right) / \mathrm{AOO} ; \mathrm{c}\right) \mathrm{AOO} / \mathrm{gold}(\mathrm{Au}) / \mathrm{AOO}$; d) $\mathrm{AOO} / \mathrm{Neh} /$ toluene diisocyanate (TDI); d) AOO/Neh/TDI; e) AOO/TiO $/$ TDI; f) AOO/Au/TDI; g) TDI/Neh/TDI; h) TDI/TiO $/$ TDI; i) TDI/Au/TDI.

complete control group. NP-exposed, TDI-sensitised and -challenged mice had significantly higher neutrophil, but not eosinophil, counts compared with the TDI/Veh/TDI group.

Table 1 shows the average levels of BAL cytokines. We found significant increased levels of MMP-9 in all TDI-sensitised and challenged mice, compare to the complete control group. MIP-2 levels were only increased in the NP-exposed, TDI-sensitised and -challenged mice. TNF- $\alpha$ levels were increased in the NPexposed, nonsensitised but TDI-challenged groups, compared to the $\mathrm{AOO} / \mathrm{Veh} / \mathrm{AOO}$ group. However, the level of TNF- $\alpha$ in the TDI/Au/TDI group was significantly decreased compared to the TDI/Veh/TDI group. IL-6 was significantly decreased in the TDI/Au/TDI group compared to the $\mathrm{AOO} / \mathrm{Veh} / \mathrm{AOO}$ group. Levels of MCP-1 were similar in all groups.

In figure $4 \mathrm{a}, \mathrm{b}$ and $\mathrm{c}$, representative images of BAL macrophages in the TDI-sensitised and -challenged mice with or without NP exposure are shown. Figure $4 \mathrm{~d}$ shows the percentage of macrophages that had taken up NPs. In the groups not exposed to NPs, no macrophages with NPs were found; therefore, these groups were not included in the statistical analysis. In both the $\mathrm{TiO}_{2}$ - and in the Au-exposed groups, significant differences were found between the nonsensitised and TDI-sensitised mice. We also find a significantly higher percentage of macrophages with $\mathrm{TiO}_{2}$ uptake compared with Au uptake in the nonsensitised but TDI-challenged control group $\left(\mathrm{AOO} / \mathrm{TiO}_{2} / \mathrm{TDI}\right.$ versus $\mathrm{AOO} /$ $\mathrm{Au} / \mathrm{TDI})$.

Clusters of electron-dense particles were evident in the cytoplasm of macrophages in cytospin preparations from mice exposed to either $\mathrm{Au}$ or $\mathrm{TiO}_{2} \mathrm{NPs}$ (fig. $4 \mathrm{e}$ and f). The composition of these particles was established by microanalysis (fig. $4 \mathrm{~g}$ and $\mathrm{h}$ ). No particle clusters were found in control samples. 


\section{Histological lesion scoring}

Figure 5 shows images of H\&E stained lungs $(50 \times$ and $400 \times$ magnification) and a histological scoring of the different groups is shown in figure 6. The complete control group, $\mathrm{AOO} / \mathrm{Veh} / \mathrm{AOO}$, did not show any signs of oedema, epithelial damage, or macrophage or neutrophil inflammation, either perivascular or peribronchial. Since the semiquantitative score for the AOO/Veh/AOO group was 0 overall, we could not perform statistical comparisons with this complete control group. The lungs of the TDI/Veh/TDI group showed a slight neutrophilic inflammation, oedema and limited epithelial damage. The lungs of the TDI/ $\mathrm{TiO}_{2} / \mathrm{TDI}$ showed significantly more macrophage infiltration compared with the TDI/Veh/ TDI group, while the TDI/Au/TDI group shows significantly more macrophage and neutrophilic inflammation, oedema and epithelial damage compared with the TDI/Veh/TDI mice.

\section{Total serum IgE}

Table 2 shows total serum IgE concentrations. TDI-sensitised and -challenged mice, with or without NP exposure, have a
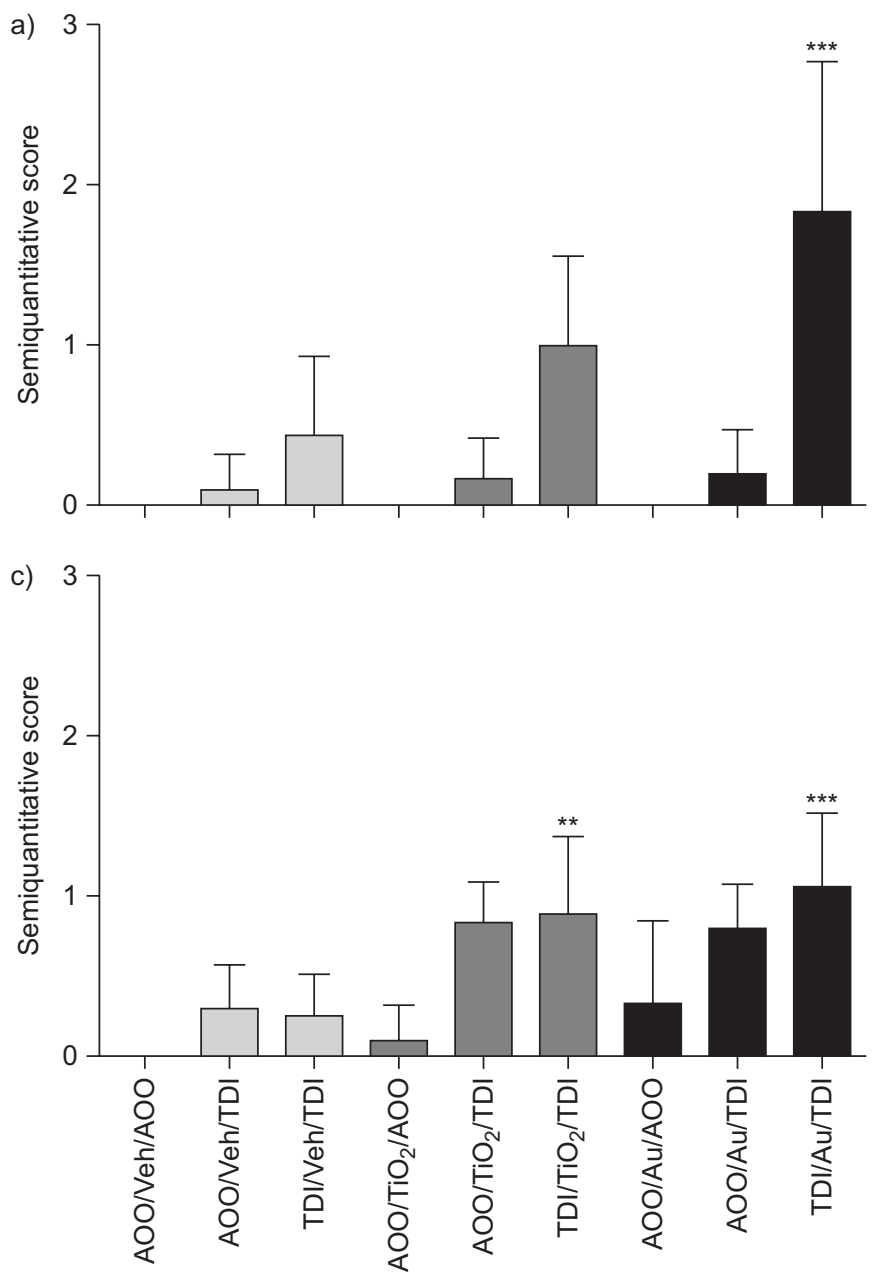

significantly higher total serum IgE concentrations as compared with their control groups. No difference was measured between the TDI-sensitised and -challenged groups.

\section{DISCUSSION}

A critical look at the available literature emphasises the need for assessment of NP-induced effects in occupationally exposed/sensitised individuals [14, 15, 35, 36]. Only a few studies have investigated the modulation of disease by nanoparticles [37, 38]. This is the first study describing the aggravation of both pulmonary function and inflammation due to NP exposure in a murine model of diisocyanate-induced occupational asthma, as shown by an increase in airway reactivity, BAL macrophages and neutrophils, and increased oedema and epithelial damage.

There are no reports available in the literature on the effects of $\mathrm{TiO}_{2}$ and $\mathrm{Au}$ NPs on AHR alone or in diseased animal models. In our experiments, the AHR (increased R), was only significantly enhanced by Au NPs in sensitised animals. This is consistent with particle exposure (carbon black NPs and

b)

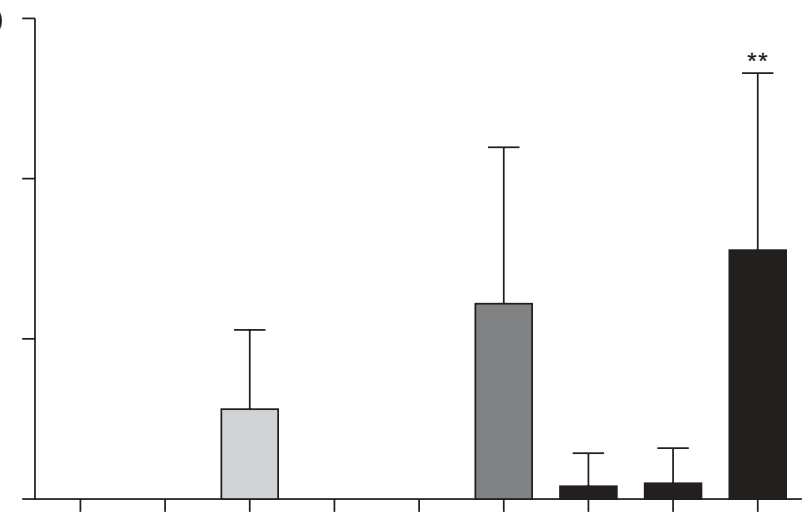

d)

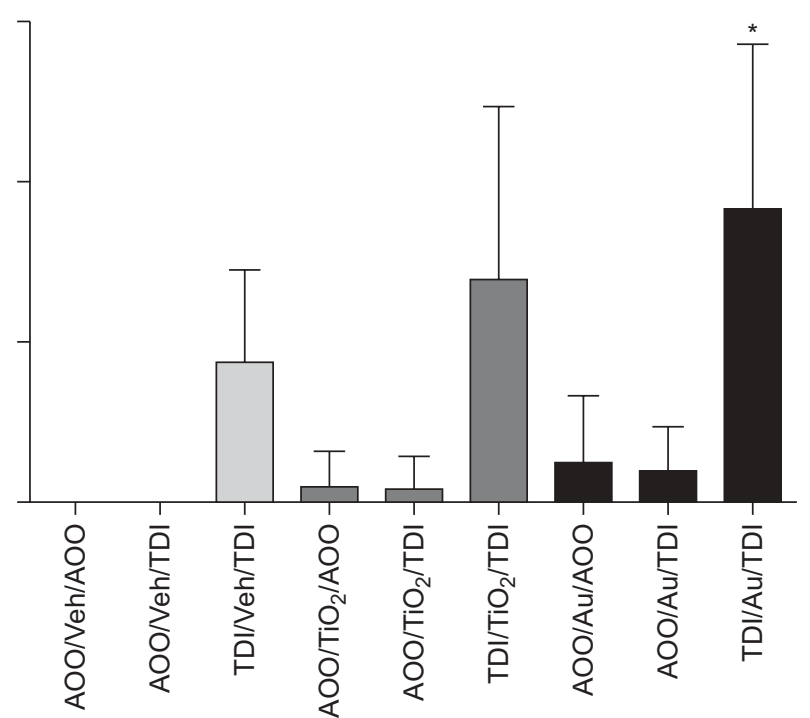

FIGURE 6. Semiquantitative scoring of lung histology. Lungs were isolated and fixed with formaldehyde. Semifine sections were cut after paraffin embedding. Slides were stained with haematoxylin and eosin, and analysed for pathological lesions. A semiquantitative scoring, ranging from 0 (nothing) to 3 (substantial), of a) oedema accumulation, b) epithelial damage, and c) macrophage and d) neutrophil infiltration was performed in a blinded manner. $n=5-9$. Experimental groups are identical to figure 2. A: acetone; OO: olive oil; Veh: vehicle; TDI: toluene diisocyanate; $\mathrm{TiO}_{2}$ : titanium dioxide; Au: gold. *: $p<0.05$ compared with TDINeh/TID; **: $p<0.01$ compared with TDI/Neh/TID; ***: p<0.001 compared with TDI/Neh/TID. 
TABLE 2 Total serum immunoglobulin (lg)E

\begin{tabular}{|c|c|}
\hline Experimental group & $\lg E \mathrm{ng} \cdot \mathrm{mL}^{-1}$ \\
\hline AOO/Veh/AOO & $272 \pm 160$ \\
\hline AOO/Veh/TDI & $276 \pm 174$ \\
\hline TDI/Veh/TDI & $2359 \pm 1703^{*}$ \\
\hline $\mathrm{AOO} / \mathrm{TiO}_{2} / \mathrm{AOO}$ & $339 \pm 286$ \\
\hline $\mathrm{AOO} / \mathrm{TiO}_{2} / \mathrm{TDI}$ & $271 \pm 255$ \\
\hline $\mathrm{TDI} / \mathrm{TiO}_{2} / \mathrm{TDI}$ & $2548 \pm 2237^{*}$ \\
\hline $\mathrm{AOO} / \mathrm{Au} / \mathrm{AOO}$ & $315 \pm 193$ \\
\hline $\mathrm{AOO/Au/TDI}$ & $229 \pm 140$ \\
\hline TDI/Au/TDI & $2699 \pm 1844^{*}$ \\
\hline
\end{tabular}

Data are presented as mean \pm SD. Total serum IgE levels were analysed $24 \mathrm{~h}$ after the toluene diisocyanate (TDI) challenge. $n=5-9$. Experimental groups are identical to figure 2. A: acetone; OO: olive oil; Veh: vehicle; $\mathrm{TiO}_{2}$ : titanium dioxide; Au: gold. *: $p<0.05$ compared with $\mathrm{AOO} / \mathrm{Neh} / \mathrm{AOO}$

diesel exhaust particles) in a mouse model of ovalbumin (OVA)induced asthma [39, 40]. The increased sensitivity to methacholine was probably the result of the increased lung inflammation and the damage of the lung epithelium. Moreover, there was no effect on $C$ in response to methacholine provocation, suggesting an influence of inflammation on the hypersensitivity rather than structural changes of the lung tissue.

Airway inflammation plays a key role in various pathologies, including asthma. Some studies have demonstrated that $\mathrm{TiO}_{2}$ NPs have the potential to induce lung inflammation in laboratory animals [26, 41, 42] but there is no information available for Au NPs. In this study we have used a low dose of NPs, inducing only a minimal pulmonary response. Previously published studies obtained inflammatory response at much higher doses (usually $\sim 5 \mathrm{mg} \cdot \mathrm{kg}^{-1}$ ), while we have used only $0.8 \mathrm{mg} \cdot \mathrm{kg}^{-1}\left(\sim 16 \mu \mathrm{g} \cdot \mathrm{mouse}^{-1}\right)$. At this particular dose we only found a mild cellular inflammatory response in NP-exposed, nonsensitised animals, which was mainly comprised of macrophages, without a significant influx of neutrophils and/or eosinophils. Moreover, the percentage, and therefore also the number, of macrophages in the BAL fluid that were associated with NPs was significantly higher in sensitised animals. EDX analysis of the particles in the macrophages revealed that these were the actual NPs to which the mice were exposed, indicating that the NPs reached the lungs and were internalised by the macrophages. Also, the control mice that received NPs barely responded to methacholine in $R$ and $C$. This indicates that NP exposure without TDI sensitisation, but with TDI challenge, does not induce hypersensitivity, and induces only limited lung damage.

The current time-weighted average values for a single shift for $\mathrm{TiO}_{2}$ vary between 15 and $1.5 \mathrm{mg} \cdot \mathrm{m}^{-3}$ [43]. When we recalculate the dose used in the mice $\left(0.8 \mathrm{mg} \cdot \mathrm{kg}^{-1}\right)$ for a human of $70 \mathrm{~kg}$, it is equivalent to $56 \mathrm{mg} \mathrm{TiO}_{2}$. This means that a worker exposed to $6 \mathrm{mg} \cdot \mathrm{m}^{-3}$, inhaling on average $10 \mathrm{~m}^{3}$ per work day, is inhaling $\sim 60 \mathrm{mg} \mathrm{TiO}_{2}$. Of course, we are aware that only a fraction of this inhaled dust reaches and remains in the lung, but this illustrates very well that the dose used is relatively realistic, certainly when taking into account that workers are exposed daily to particles in the air.

Our results demonstrate the aggravation of pulmonary inflammation (both at the cellular level and at the level of cytokine and chemokine production) by NPs even at the low doses used. We observed a four-fold increase in neutrophil counts in the case of sensitised animals exposed to $\mathrm{Au}$ and a 2.5-fold increase in sensitised animals exposed to $\mathrm{TiO}_{2} \mathrm{NPs}$. Studies in an OVA asthma model have described the potency of carbon black [38] and diesel exhaust particles to increase the allergen-induced pulmonary inflammation [39, 40]. A recent study with latex NPs has shown the inability of NPs to increase eosinophilic lung inflammation in the OVA model of asthma [44]. Modulation of OVA-induced asthma in mouse model by TDI [45] or bakery flour has also been reported [46]. Particle exposure in the lung leads to macrophage recruitment and, during concomitant challenge with TDI, a significant augmentation of neutrophilic chemoattraction was observed. It has been shown that activated alveolar macrophages can lead to the recruitment of neutrophils [47] and macrophage products (MIP-2 and cytokine-induced neutrophil chemoattractant/ growth-regulated oncogene) play a direct role in neutrophil recruitment in infected lungs [48]. Furthermore, it has been shown that macrophages release a neutrophil chemoattractant, macrophage-derived neutrophil chemotactic factor, when incubated with lipopolysaccharide, IL-8, TNF- $\alpha$ and interferon- $\gamma$ [49]. In our experiments, we found the highest levels of TNF- $\alpha$ in the nonsensitised, NP-exposed and TDIchallenged mice, and not in the NP-exposed, TDI-sensitised and TDI-challenged mice, suggesting that other pathways are activated in sensitised mice, compared to nonsensitised mice.

In our study, NPs did not affect the IgE levels. Previously, in an OVA model of respiratory allergy, modulating effects of ambient air particles, diesel exhaust and wood smoke particles were observed [50-52]. In our study, the presence of total IgE in serum serves as a good marker of prior sensitisation in mice, but has limited functional consequences. This confirms the hypothesis of a non-IgE-mediated cellular mechanism involved in the development of chemically induced asthma.

Histological lesions consisted of perivascular and peribronchial neutrophilic and macrophage infiltration, shedding and necrosis of the epithelium, and eodema. Histological lesion scoring further indicated that the severity of pathological response in sensitised mice was significantly increased in $\mathrm{Au}$ NP exposure. Macrophages readily engulfed these particles, which was apparent as pigmentation in the histological sections.

The mechanism of NP-induced modulation of asthma is still unclear. NP-induced oxidative damage could be one of the leading factors, as oxidative stress plays an important role in the pathogenesis of asthma, and we have already shown the ability of these NPs to provoke oxidative stress in cultured bronchial epithelial cells [28, 31, 53]. Another possible mechanism might be particle-induced epithelial damage to the respiratory barrier, which leads to increased susceptibility to allergens [54-56]. Consistent with this, it has also been shown that MMP-9 modulates the tight junction integrity of the airway epithelium, thereby initiating lung tissue remodeling [57]. Furthermore, NPs also have a direct influence on the 
maturation, antigen presentation and costimulation of antigen presenting cells, as reported by PALOMÄKI et al. [58].

We expected some substantial differences between the two particles in sensitised mice. The findings are a little counterintuitive because we anticipated that the crystalline $\mathrm{TiO}_{2}$ particles [59] would induce a more severe inflammatory response compared with the colloidal $\mathrm{Au}$, which is supposed to be less inflammatory [60]. Notwithstanding the significant differences between the two particles in chemistry, physical appearance, size, etc., both induced a strong influx of inflammatory cells in the lung, and a significant increase in MMP-9 and MIP-2, but a relative low proinflammatory signal (TNF- $\alpha$ and IL-6) in TDI-sensitised mice.

In conclusion, we have demonstrated that Au NPs aggravate airway hyperreactivity and the inflammatory response in TDIsensitised animals, while $\mathrm{TiO}_{2}$ NPs only significantly increase the inflammatory response in TDI-sensitised animals. These results indicate the possibility of aggravation of chemically induced occupational asthma in the presence of NP exposure. Further studies are warranted to understand the mechanisms underlying this aggravation of asthmatic responses.

\section{SUPPORT STATEMENT}

The study was supported by Agence Nationale de la Recherche grant numbers 059 9-05 SET 024-01 and 06 SEST 24-01, Caisse d'Assurance Maladie des Professions Liberales de Province, Paris, France, Legs Poix, the Interuniversity Attraction Pole Program (P6/35) and the Research Foundation of Flanders (FWO G.0547.08). J.A.J. Vanoirbeek is a postdoctoral fellow of the FWO and S. Hussain is a doctoral fellow of Higher Education Commission (Pakistan).

\section{STATEMENT OF INTEREST}

None declared.

\section{REFERENCES}

1 Malo JL, Lemiere C, Gautrin D, et al. Occupational asthma. Curr Opin Pulm Med 2004; 10: 57-61.

2 Boulet LP, Lemiere C, Gautrin D, et al. New insights into occupational asthma. Curr Opin Allergy Clin Immunol 2007; 7: 96-101.

3 Bello D, Herrick CA, Smith TJ, et al. Skin exposure to isocyanates: reasons for concern. Environ Health Perspect 2007; 115: 328-335.

4 Vanoirbeek JA, Tarkowski M, Ceuppens JL, et al. Respiratory response to toluene diisocyanate depends on prior frequency and concentration of dermal sensitization in mice. Toxicol Sci 2004; 80: 310-321.

5 Tarkowski M, Vanoirbeek JA, Vanhooren HM, et al. Immunological determinants of ventilatory changes induced in mice by dermal sensitization and respiratory challenge with toluene diisocyanate. Am J Physiol Lung Cell Mol Physiol 2007; 292: L207-L214.

6 Vanoirbeek JA, De Vooght V, Vanhooren HM, et al. How long do the systemic and ventilatory responses to toluene diisocyanate persist in dermally sensitized mice? J Allergy Clin Immunol 2008; 121: 456-463.

7 Redlich CA, Herrick CA. Lung/skin connections in occupational lung disease. Curr Opin Allergy Clin Immunol 2008; 8: 115-119.

8 Petsonk EL, Wang ML, Lewis DM, et al. Asthma-like symptoms in wood product plant workers exposed to methylene diphenyl diisocyanate. Chest 2000; 118: 1183-1193.

9 Pronk A, Preller L, Raulf-Heimsoth M, et al. Respiratory symptoms, sensitization, and exposure response relationships in spray painters exposed to isocyanates. Am J Respir Crit Care Med 2007; 176: 1090-1097.

10 Ban M, Morel G, Langonne I, et al. TDI can induce respiratory allergy with Th2-dominated response in mice. Toxicology 2006; 218: $39-47$.

11 Herrick CA, Das J, Xu L, et al. Differential roles for CD4 and CD8 T cells after diisocyanate sensitization: genetic control of TH2induced lung inflammation. J Allergy Clin Immunol 2003; 111: 1087-1094.

12 De Vooght V, Cruz MJ, Haenen S, et al. Ammonium persulfate can initiate an asthmatic response in mice. Thorax 2010; 65: 252-257.

13 The Project on Emerging Nanotechnologies. Woodrow Wilson Database. www.nanotechproject.org. Date last accessed: October 2009. Date last updated: August 2009.

14 Song Y, Li X, Du X. Exposure to nanoparticles is related to pleural effusion, pulmonary fibrosis and granuloma. Eur Respir J 2009; 34: 559-567.

15 Gilbert N. Nanoparticle safety in doubt. Nature 2009; 460: 937.

16 Xia T, Kovochich M, Brant J, et al. Comparison of the abilities of ambient and manufactured nanoparticles to induce cellular toxicity according to an oxidative stress paradigm. Nano Lett 2006; 6: 1794-807.

17 Kaida T, Kobayashi K, Adachi M, et al. Optical characteristics of titanium oxide interference film and the film laminated with oxides and their applications for cosmetics. J Cosmet Sci 2004; 55: 219-220.

18 Long TC, Tajuba J, Sama P, et al. Nanosize titanium dioxide stimulates reactive oxygen species in brain microglia and damages neurons in vitro. Environ Health Perspect 2007; 115: 1631-1637.

19 Sperling RA, Rivera GP, Zhang F, et al. Biological applications of gold nanoparticles. Chem Soc Rev 2008; 37: 1896-1908.

20 Ghosh P, Han G, De M, et al. Gold nanoparticles in delivery applications. Adv Drug Deliv Rev 2008; 60: 1307-1315.

21 De Wall SL, Painter C, Stone JD, et al. Noble metals strip peptides from class II MHC proteins. Nat Chem Biol 2006; 2: 197-201.

22 Cheng Y, Samia C, Meyers JD, et al. Highly efficient drug delivery with gold nanoparticle vectors for in vivo photodynamic therapy of cancer. J Am Chem Soc 2008; 130: 10643-10647.

23 Novelli F, Recine M, Sparatore F, et al. Gold(I) complexes as antimicrobial agents. Farmaco 1999; 54: 232-236.

24 Frampton MW, Utell MJ, Zareba W, et al. Effects of exposure to ultrafine carbon particles in healthy subjects and subjects with asthma. Res Rep Health Eff Inst, 2004: 1-47.

25 von Klot S, Wolke G, Tuch T, et al. Increased asthma medication use in association with ambient fine and ultrafine particles. Eur Respir J 2002; 20: 691-702.

26 Warheit DB, Webb TR, Sayes CM, et al. Pulmonary instillation studies with nanoscale $\mathrm{TiO}_{2}$ rods and dots in rats: toxicity is not dependent upon particle size and surface area. Toxicol Sci 2006; 91: 227-236.

27 Sayes CM, Reed KL, Warheit DB. Assessing toxicity of fine and nanoparticles: comparing in vitro measurements to in vivo pulmonary toxicity profiles. Toxicol Sci 2007; 97: 163-180.

28 Hussain S, Boland S, Baeza-Squiban A, et al. Oxidative stress and proinflammatory effects of carbon black and titanium dioxide nanoparticles: role of particle surface area and internalized amount. Toxicology 2009; 260: 142-149.

29 Val S, Hussain S, Boland S, et al. Carbon black and titanium dioxide nanoparticles induce pro-inflammatory responses in bronchial epithelial cells: need for multiparametric evaluation due to adsorption artifacts. Inhal Toxicol 2009; 21: 115-122.

30 Karlsson HL, Gustafsson J, Cronholm P, et al. Size-dependent toxicity of metal oxide particles: a comparison between nano- and micrometer size. Toxicol Lett 2009; 188: 112-118.

31 Hussain S, Thomassen LC, Ferecatu I, et al. Carbon black and titanium dioxide nanoparticles elicit distinct apoptotic pathways in bronchial epithelial cells. Part Fibre Toxicol 2010; 7: 10. 
32 Berne BJ, Pecora R. Dynamic Light Scattering with Applications to Chemistry, Biology, and Physics. New York, Wiley; 1976.

33 De Vooght V, Vanoirbeek JA, Haenen S, et al. Oropharyngeal aspiration: an alternative route for challenging in a mouse model of chemical-induced asthma. Toxicology 2009; 259: 84-89.

34 Vanoirbeek JA, Rinaldi M, De Vooght V, et al. Noninvasive and invasive pulmonary function in mouse models of obstructive and restrictive respiratory diseases. Am J Respir Cell Mol Biol 2009; 42: 96-104.

35 Kahru A, Savolainen K. Potential hazard of nanoparticles: from properties to biological and environmental effects. Toxicology 2010; 269: 89-91.

36 Savolainen K, Alenius H, Norppa H, et al. Risk assessment of engineered nanomaterials and nanotechnologies: a review. Toxicology 2010; 269: 92-104

37 Larsen ST, Roursgaard M, Jensen KA, et al. Nano titanium dioxide particles promote allergic sensitization and lung inflammation in mice. Basic Clin Pharmacol Toxicol 2010; 106: 114-117.

38 Alessandrini F, Schulz H, Takenaka S, et al. Effects of ultrafine carbon particle inhalation on allergic inflammation of the lung. J Allergy Clin Immunol 2006; 117: 824-830.

39 Inoue $\mathrm{K}$, Takano H, Yanagisawa R, et al. Effects of nanoparticles on lung physiology in the presence or absence of antigen. Int $J$ Immunopathol Pharmacol 2007; 20: 737-744.

40 Takano H, Ichinose T, Miyabara Y, et al. Inhalation of diesel exhaust enhances allergen-related eosinophil recruitment and airway hyperresponsiveness in mice. Toxicol Appl Pharmacol 1998; 150: 328-337.

41 Park EJ, Yoon J, Choi K, et al. Induction of chronic inflammation in mice treated with titanium dioxide nanoparticles by intratracheal instillation. Toxicology 2009; 260: 37-46.

42 Van Ravenzwaay B, Landsiedel R, Fabian E, et al. Comparing fate and effects of three particles of different surface properties: nano- $\mathrm{TiO}_{2}$, pigmentary $\mathrm{TiO}_{2}$ and quartz. Toxicol Lett 2009; 186: 152-159.

43 NIOSH. Evaluation of Health Hazard and Recommandations for Occupational Exposure to Titanium Dioxide. www.cdc.gov/niosh/ review/public/tio2/pdfs/TIO2Draft.pdf Date last accessed: November, 2010. Date last updated: November 22, 2005.

44 Inoue $\mathrm{K}$, Takano $\mathrm{H}$, Yanagisawa $\mathrm{R}$, et al. Size effects of latex nanomaterials on lung inflammation in mice. Toxicol Appl Pharmacol 2009; 234: 68-76.

45 Ban M, Langonne I, Huguet $\mathrm{N}$, et al. Inhaled chemicals may enhance allergic airway inflammation in ovalbumin-sensitised mice. Toxicology 2006; 226: 161-171.
46 Marraccini P, Brass DM, Hollingsworth JW, et al. Bakery flour dust exposure causes non-allergic inflammation and enhances allergic airway inflammation in mice. Clin Exp Allergy 2008; 38: 1526-1535.

47 Robbins RA, Russ WD, Thomas KR, et al. Complement component C5 is required for release of alveolar macrophage-derived neutrophil chemotactic activity. Am Rev Respir Dis 1987; 135: 659-664.

48 Hashimoto S, Pittet JF, Hong K, et al. Depletion of alveolar macrophages decreases neutrophil chemotaxis to Pseudomonas airspace infections. Am J Physiol 1996; 270: L819-L828.

49 Desouza IA, Hyslop S, Franco-Penteado CF, et al. Mouse macrophages release a neutrophil chemotactic mediator following stimulation by staphylococcal enterotoxin type A. Inflamm Res 2001; 50: 206-212.

50 Alberg T, Cassee FR, Groeng EC, et al. Fine ambient particles from various sites in europe exerted a greater $\operatorname{IgE}$ adjuvant effect than coarse ambient particles in a mouse model. J Toxicol Environ Health A 2009; 72: 1-13.

51 Nygaard UC, Samuelsen M, Aase A, et al. The capacity of particles to increase allergic sensitization is predicted by particle number and surface area, not by particle mass. Toxicol Sci 2004; 82: 515-524.

52 Samuelsen M, Nygaard UC, Lovik M. Allergy adjuvant effect of particles from wood smoke and road traffic. Toxicology 2008; 246: 124-131.

53 Riedl MA, Nel AE. Importance of oxidative stress in the pathogenesis and treatment of asthma. Curr Opin Allergy Clin Immunol 2008; 8: 49-56.

54 van Zijverden M, Granum B. Adjuvant activity of particulate pollutants in different mouse models. Toxicology 2000; 152: 69-77.

55 Murphy SA, BeruBe KA, Pooley FD, et al. The response of lung epithelium to well characterised fine particles. Life Sci 1998; 62: 1789-1799.

56 Devalia JL, Rusznak C, Davies RJ. Allergen/irritant interaction: its role in sensitization and allergic disease. Allergy 1998; 53: 335-345.

57 Vermeer PD, Denker J, Estin M, et al. MMP9 modulates tight junction integrity and cell viability in human airway epithelia. Am J Physiol Lung Cell Mol Physiol 2009; 296: L751-L762.

58 Palomäki J, Karisola P, Pylkkanen L, et al. Engineered nanomaterials cause cytotoxicity and activation on mouse antigen presenting cells. Toxicology 2010; 267: 125-131.

59 Monteiller C, Tran L, MacNee W, et al. The pro-inflammatory effects of low-toxicity low-solubility particles, nanoparticles and fine particles, on epithelial cells in vitro: the role of surface area. Occup Environ Med 2007; 64: 609-615.

60 Jacobsen NR, Moller P, Jensen KA, et al. Lung inflammation and genotoxicity following pulmonary exposure to nanoparticles in $\mathrm{ApoE}^{-/-}$mice. Part Fibre Toxicol 2009; 6: 2. 